University of Wollongong

Research Online

Australian Institute for Innovative Materials -

Papers

Australian Institute for Innovative Materials

$1-1-2015$

Guanidinium octahydrotriborate: an ionic liquid with high hydrogen storage capacity

Weidong Chen

Chinese Academy of Sciences

Zhenguo Huang

University of Wollongong, zhenguo@uow.edu.au

Guotao Wu

Chinese Academy of Sciences

Teng He

Chinese Academy of Sciences

Zhao Li

Chinese Academy of Sciences

See next page for additional authors

Follow this and additional works at: https://ro.uow.edu.au/aiimpapers

Part of the Engineering Commons, and the Physical Sciences and Mathematics Commons

Research Online is the open access institutional repository for the University of Wollongong. For further information contact the UOW Library: research-pubs@uow.edu.au 


\title{
Guanidinium octahydrotriborate: an ionic liquid with high hydrogen storage capacity
}

\author{
Abstract \\ For chemical hydrogen storage, capacity is one key criterion that has spurred intense efforts to \\ investigate compounds with high hydrogen content. The guanidinium cation and the octahydrotriborate \\ anion possess $6 \mathrm{H}^{+}$and $8 \mathrm{H}^{-}$, respectively. The combination of these two ions yields guanidinium \\ octahydrotriborate with $13.8 \mathrm{wt} \%$ hydrogen. This paper presents its facile synthesis, as confirmed by ${ }^{11} \mathrm{~B}$ \\ and ${ }^{1} \mathrm{H}$ nuclear magnetic resonance spectroscopy. The results show that guanidinium octahydrotriborate \\ is an ionic liquid with a melting point below $-10^{\circ} \mathrm{C}$, which makes it a possible injectable/pumpable \\ hydrogen carrier. It decomposes selectively to hydrogen, in stark contrast to the formation of various \\ boranes from related solid octahydrotriborates. The much improved $\mathrm{H}_{2}$ purity can be ascribed to the more \\ effective combination of $\mathrm{H}^{+}$and $\mathrm{H}^{-}$, and the higher $\mathrm{H}^{+} / \mathrm{H}^{-}$ratio in liquid guanidinium octahydrotriborate.

\section{Keywords} \\ capacity, storage, liquid, hydrogen, ionic, high, guanidinium, octahydrotriborate

\section{Disciplines} \\ Engineering | Physical Sciences and Mathematics

\section{Publication Details} \\ Chen, W., Huang, Z., Wu, G., He, T., Li, Z., Chen, J., Guo, Z., Liu, H. \& Chen, P. (2015). Guanidinium \\ octahydrotriborate: an ionic liquid with high hydrogen storage capacity. Journal of Materials Chemistry $A$, \\ $3(21), 11411-11416$.
}

\section{Authors}

Weidong Chen, Zhenguo Huang, Guotao Wu, Teng He, Zhao Li, Juner Chen, Zaiping Guo, Hua-Kun Liu, and Ping Chen 


\title{
Journal Name
}

\section{ARTICLE}

\section{Guanidinium octahydrotriborate: An ionic liquid with a high hydrogen capacity}

\author{
Weidong Chen, ${ }^{a, b}$ Zhenguo Huang, ${ }^{c^{*}}$ Guotao Wu, ${ }^{a}$ Teng He, ${ }^{a}$ Zhao Li, ${ }^{a}$ Juner \\ Chen, ${ }^{a}$ Zaiping Guo, ${ }^{c}$ Huakun Liu $^{c}$ and Ping Chen ${ }^{a *}$.
}

For chemical hydrogen storage, capacity is one key criterion that has spurred intense efforts to investigate compounds with high hydrogen content. The guanidinium cation and the octahydrotriborate anion possess $6 \mathrm{H}^{+}$and $8 \mathrm{H}^{-}$, respectively. The combination of these two ions yields guanidinium octahydrotriborate with $13.8 \mathrm{wt}$ \% hydrogen. This paper presents its facile synthesis, as confirmed by ${ }^{11} \mathrm{~B}$ and ${ }^{1} \mathrm{H}$ nuclear magnetic resonance spectroscopy. The results show that guanidinium octahydrotriborate is an ionic liquid with a melting point below $-10^{\circ} \mathrm{C}$, which makes it a possible injectable/pumpable hydrogen carrier. It decomposes selectively to hydrogen, in stark contrast to the formation of various boranes from related solid octahydrotriborates. The much improved $\mathrm{H}_{2}$ purity can be ascribed to the more effective combination of $\mathrm{H}^{+}$and $\mathrm{H}^{-}$, and the higher $\mathrm{H}^{+} / \mathrm{H}^{-}$ratio in the liquid guanidinium octahydrotriborate.

\section{Introduction}

Hydrogen has been considered as a clean and efficient energy carrier to store electricity generated by wind and solar farms and to deliver the energy upon demand. The current means of storing hydrogen, however, are either not safe, not compact, or too energy intensive. These disadvantages constitute a big barrier to the wide deployment of devices powered by hydrogen, in particular, where both volumetric and gravimetric densities are critical. Material-based hydrogen storage has thus been intensively studied, since it outperforms traditional storage via high pressure or cryogenic tanks. ${ }^{1}$ Among all the materials studied, hydrogen-rich alanates, amides, and borohydrides consisting of light elements have attracted particularly intense attention. ${ }^{2}$ Due to the light atomic weight, boron-nitrogen-hydrogen-containing compounds (abbreviated as BNH) could also possess remarkably high hydrogen content. ${ }^{1-10}$ Alkali/alkaline metal borohydrides and ammonia borane have therefore been extensively investigated. ${ }^{9}$ Despite their intrinsic high hydrogen content, they suffer from serious problems, such as slow kinetics, problematic by-products, or unfavourable thermodynamics, ${ }^{11-14}$ which make them unsuitable for practical application.

Strategies such as introducing additives and making derivatives have been employed to suppress the formation of impurities and/or enhance the kinetics. For example, replacing $\mathrm{H}$ atom on the $\mathrm{N}$ by $\mathrm{Li} / \mathrm{Na}$ or Ca can effectively suppress the formation of by-products from ammonia borane, ${ }^{15,16}$ and introducing $\mathrm{MgH}_{2}$ can effectively destabilize $\mathrm{LiBH}_{4}$ and improve its dehydrogenation kinetics. ${ }^{17}$ Its performance, however, still falls short of the criteria. New BNH compounds have thus been synthesized and screened. BNH compounds feature protic $\mathrm{H}\left(\mathrm{H}^{+}\right)$on $\mathrm{N}$ and hydridic $\mathrm{H}\left(\mathrm{H}^{-}\right)$on $\mathrm{B}$ atoms, which normally results in an extensive dihydrogen bond network throughout the crystal structure. ${ }^{18}$ The formation of $\mathrm{H}_{2}$ via the combination of $\mathrm{H}^{+}$and $\mathrm{H}^{-}$features a high enthalpy $\left(\mathrm{H}^{+}+\mathrm{H}^{-}=\mathrm{H}_{2}, \Delta H=-17.37 \mathrm{eV}\right)$, which is considered as one of the driving forces of dehydrogenation. ${ }^{10,19}$ To take advantage of these $\mathrm{H}^{+}$--- $\mathrm{H}^{-}$interactions, $\mathrm{H}^{+}$containing units have been introduced to destabilize borohydrides that contain four $\mathrm{H}^{-}$atoms. Several borohydride/ammonia ${ }^{20-22}$ and borohydride/amide ${ }^{23,24}$ systems have thus been developed. Other $\mathrm{N}-\mathrm{H}$ containing units such as guanidinium $\left(\mathrm{C}\left(\mathrm{NH}_{2}\right)_{3}\right)$ have also been employed. ${ }^{25-29}$ The interaction between $\mathrm{H}^{+}$and $\mathrm{H}^{-}$observed in guanidinium borohydride leads to a low activation energy pathway for $\mathrm{H}_{2}$ evolution. ${ }^{25}$ The excess $\mathrm{H}^{+}$in guanidinium borohydride can be offset by introducing $\mathrm{LiBH}_{4}$ or $\mathrm{Ca}\left(\mathrm{BH}_{4}\right)_{2}$, and these have been reported to suppress the formation of ammonia from pristine guanidinium borohydride. ${ }^{20,21}$ Compared with the well-studied borohydrides (also known as tetrahydroborate (with $\mathrm{BH}_{4}^{-}$)), octahydrotriborates (with $\mathrm{B}_{3} \mathrm{H}_{8}{ }^{-}$) have recently attracted considerable interest. They have been proposed as an intermediate during the thermal decomposition of borohydrides. ${ }^{30}$ Sodium octahydrotriborate has been reported to outperform the most studied $\mathrm{NaBH}_{4}$ and $\mathrm{NH}_{3} \mathrm{BH}_{3}$ for hydrogen storage via hydrolysis. ${ }^{31}$ Octahydrotriborate is also used to make ammonia triborane $\left(\mathrm{NH}_{3} \mathrm{~B}_{3} \mathrm{H}_{7}\right)$, which has shown exceptional hydrolytic properties. $^{32,33}$

For practical applications, solid hydrogen storage materials are inferior to liquid ones with respect to the control of hydrogen supply upon demand. ${ }^{19,34}$ Liquid compounds are very compati- 
ble with the current liquid fuel distribution techniques, which can offer precise control of hydrogen release in terms of rates and quantity. Their sluggish mass transfer and poor heat dissipation make the control of hydrogen release from solid materials very challenging. Ionic liquid based hydrogen carriers have thus attracted the interest of researchers. ${ }^{29,35}$

In this paper, we report guanidinium octahydrotriborate (Fig. 1) from synthesis to hydrogen release. Theoretically, guanidinium octahydrotriborate has 13.8 wt.\% hydrogen $(14 / 101=13.8$ wt.\%), and the $6 \mathrm{H}^{+}$in the $\left(\mathrm{C}\left(\mathrm{NH}_{2}\right)_{3}\right)^{+}$cation and the $8 \mathrm{H}^{-}$in the $\left(\mathrm{B}_{3} \mathrm{H}_{8}\right)^{-}$anion would contribute to a facile formation of $\mathrm{H}_{2}$. Guanidinium octahydrotriborate was once reported as a solid at $20{ }^{\circ} \mathrm{C}$ and it is not pure. ${ }^{36}$ We found, however, this compound has a melting point below $-10^{\circ} \mathrm{C}$, which makes it interesting for injectable/pumpable liquid fuel for hydrogen supply. The high hydrogen capacity could also make guanidinium octahydrotriborate a green hypergolic fuel. ${ }^{37-40}$

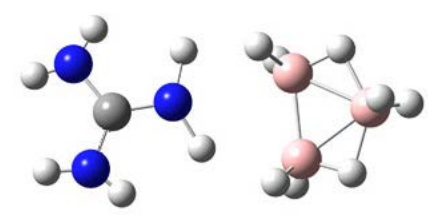

Fig. 1 Schematic diagram of the structure of guanidinium octahydrotriborate (grey, C; blue, N; pink, B; white, H).

\section{Experimental}

\section{Reagents}

Guanidinium chloride (98\%) was purchased from Alfa Aesar and used as received. Tetrahydrofuran (THF) was purchased from Merck (liquid chromatography grade, $\geq 99.9 \%$ ). Sodium octahydrotriborate $\left(\mathrm{NaB}_{3} \mathrm{H}_{8},>97 \%\right)$ was prepared following the method reported. ${ }^{41}$

\section{Characterization}

Solvent nuclear magnetic resonance spectroscopy (NMR) and solid-state magic-angle-spinning nuclear magnetic resonance spectroscopy (MAS NMR) were performed on a Bruker Avance $500 \mathrm{MHz}$ spectrometer equipped with liquid and solid detectors, respectively. Solution ${ }^{1} \mathrm{H}$ NMR was referenced to $\mathrm{CD}_{3} \mathrm{CN}$ and ${ }^{11} \mathrm{~B} \mathrm{NMR}$ to $\mathrm{BF}_{3} \cdot \mathrm{Et}_{2} \mathrm{O}$. Powder X-ray diffraction (XRD) characterization was performed on a PANalytical X'Pert diffractometer (Cu K $\alpha, 40 \mathrm{kV}, 40 \mathrm{~mA}$ ) with a self-made sample holder that protects the samples from exposure to air. Temperature programmed desorption (TPD) coupled with a mass spectrometer (MS, Hiden Analytical HPR 20) (TPD-MS) was employed to analyse the released gas. Volumetric release measurements (VR) were performed on a Sieverts apparatus. ${ }^{42}$ Decomposition in the solvents was conducted in an autoclave fitted with a pressure detector. Both solution NMR and solid state MAS NMR were used to characterize the intermediates and final products. Fourier-transform infrared (FT-IR) data were collected on a Varian 3100 FTIR spectrophotometer (Varian, USA, Excalibar Series) in the diffuse reflection infrared Fourier transform spectroscopy (DRIFT) mode. Low tempera- ture differential scanning calorimetry (DSC) was performed on a Netzsch DSC 204 unit (Netzsch) with a heating rate of 2 ${ }^{\circ} \mathrm{C} / \mathrm{min}$. Differential thermal analysis (DTA) measurements were carried out on a Netzsch STA449C thermal analysis system (Netzsch) with a heating rate of $2{ }^{\circ} \mathrm{C} / \mathrm{min}$. All the manipulations were carried out in an air-free environment.

\section{Results and Discussion}

\section{Synthesis}

For the synthesis of guanidinium octahydrotriborate, $\mathrm{NaB}_{3} \mathrm{H}_{8}$ and guanidinium chloride were ball milled together in a 1:1 molar ratio at $150 \mathrm{rpm}$ for $4 \mathrm{~h}$. Guanidinium octahydrotriborate can also be produced by reacting these two starting materials in tetrahydrofuran (THF). The resultant precipitate, i.e., $\mathrm{NaCl}$, was filtered away in THF. Powder X-ray diffraction (XRD) confirmed the identity of the solid powder as $\mathrm{NaCl}$ (Supporting Information Fig. S1). Based upon the weight of $\mathrm{NaCl}$ and the quantity of the starting materials, the following reaction (Eq. 1) can be derived.

$$
\mathrm{NaB}_{3} \mathrm{H}_{8}+\mathrm{C}\left(\mathrm{NH}_{2}\right)_{3} \mathrm{Cl} \rightarrow \mathrm{C}\left(\mathrm{NH}_{2}\right)_{3} \mathrm{~B}_{3} \mathrm{H}_{8}+\mathrm{NaCl}
$$

This was corroborated by NMR studies. The ${ }^{11} \mathrm{~B}$ NMR spectrum (Fig. 2, left) indicates the integrity of the $\mathrm{B}_{3} \mathrm{H}_{8}$ unit after the reaction. The ${ }^{1} \mathrm{H}$ NMR spectrum (Fig. 2, right) confirms the coexistence of both $\mathrm{NH}_{2}$ and $\mathrm{B}_{3} \mathrm{H}_{8}$ units in a ratio close to 3:1, based upon the integration of the ${ }^{1} \mathrm{H}$ NMR resonance.
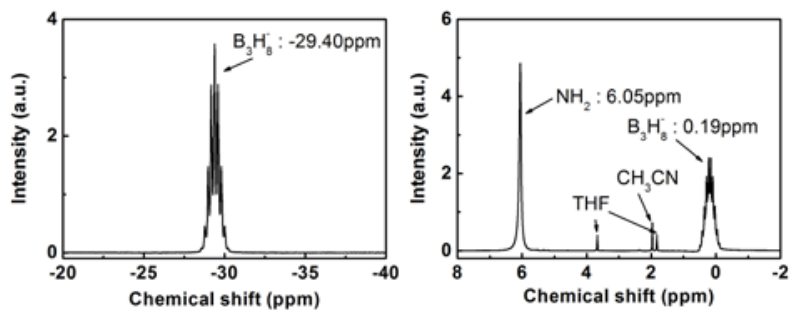

Fig. $2{ }^{11} \mathrm{~B}$ NMR (left) and ${ }^{1} \mathrm{H}$ NMR (right) spectra of the synthesized guanidinium octahydrotriborate in $\mathrm{CD}_{3} \mathrm{CN}$.

The viscous nature of the ball-milled product indicates that guanidinium octahydrotriborate has a low melting point, behaving like an ionic liquid, similar to methylguanidinium borohydride. $^{29}$ This was confirmed by a low temperature DSC measurement from $40^{\circ} \mathrm{C}$ down to $-40^{\circ} \mathrm{C}$, which revealed a melting point below $-10^{\circ} \mathrm{C}$ upon heating (Fig. S2). Guanidinium octahydrotriborate is highly miscible and stable in various solvents such as diethyl ether, acetonitrile, dichloromethane, tetrahydrofuran, 1,2-dimethoxyethane, etc. Clear solutions with concentrations ranging from $0.2 \mathrm{~mol} / \mathrm{L}$ to $10 \mathrm{~mol} / \mathrm{L}$ could be prepared in THF (Fig. S3). No obvious change was detected in the NMR characterization after 2 months in storage at $4{ }^{\circ} \mathrm{C}$. Isolation of guanidinium octahydrotriborate from several solvents was unsuccessful, since it tends to decompose during the prolonged pumping to remove solvents. In measuring the ther- 
mal decomposition of the ball-milled product, $\mathrm{NaCl}$ was not removed after synthesis. Considering the high thermal stability of $\mathrm{NaCl}$, it is believed that $\mathrm{NaCl}$ will not affect the decomposition of guanidinium octahydrotriborate. ${ }^{26,27}$

\section{Thermal decomposition of the as-prepared guanidinium octahy- drotriborate}

The TPD-MS curve (Fig. 3) shows that only $\mathrm{H}_{2}$ was detected during the heat treatment to $350{ }^{\circ} \mathrm{C}$, a big improvement in purity over that of guanidinium borohydride, where ammonia was observed as a by-product. ${ }^{25}$ Guanidinium octahydrotriborate starts to release $\mathrm{H}_{2}$ at about $70{ }^{\circ} \mathrm{C}$ and peaks at about $78{ }^{\circ} \mathrm{C}$, which are noticeably lower than for guanidinium borohydride (dehydrogenation starting at $102{ }^{\circ} \mathrm{C}$ and peaking at $110{ }^{\circ} \mathrm{C}$ ). ${ }^{25}$ A slight jump in temperature was detected, indicating that the decomposition is exothermic. This was confirmed by DTA measurement (Fig. S4).

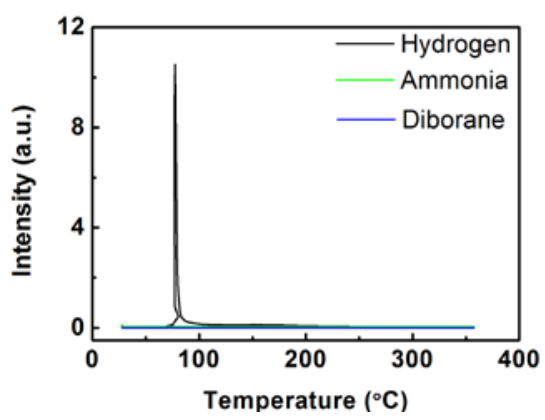

Fig. 3 TPD-MS profiles of guanidinium octahydrotriborate with a ramping rate of $2^{\circ} \mathrm{C} / \mathrm{min}$.

To quantify the hydrogen released, the as-prepared guanidinium octahydrotriborate sample from ball milling was heated at 83.5 ${ }^{\circ} \mathrm{C}$ in a closed vessel. The temperature was set to increase from $20^{\circ} \mathrm{C}$ to $85^{\circ} \mathrm{C}$ at a rate of $2{ }^{\circ} \mathrm{C} / \mathrm{min}$ and then dwell at $85^{\circ} \mathrm{C}$. Inside the vessel, the temperature was measured to be $83.5^{\circ} \mathrm{C}$. Only $\mathrm{H}_{2}$ was detectable by MS as the gaseous product. The VR results (Fig. 4) show that about 5.5 equiv. $\mathrm{H}_{2}$ was released in less than 10 minutes, corresponding to 6.9 wt.\% hydrogen, taking into account the $\mathrm{NaCl}$.
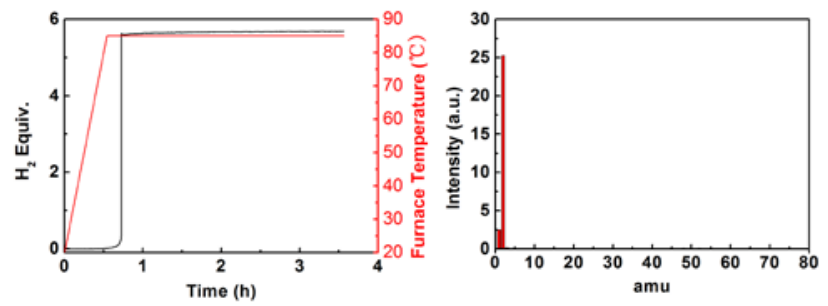

Fig. 4 Dehydrogenation of the as-prepared guanidinium octahydrotriborate at $83.5{ }^{\circ} \mathrm{C}$. Volumetric release measurement (VR) (left) and MS analysis (right).
The thermal decomposition of $\mathrm{NH}_{3} \mathrm{~B}_{3} \mathrm{H}_{7}, \mathrm{NH}_{4} \mathrm{~B}_{3} \mathrm{H}_{8}$, and $\left(\mathrm{NH}_{3}\right)_{2} \mathrm{BH}_{2} \mathrm{~B}_{3} \mathrm{H}_{8}$ gives off noticeable amount of $\mathrm{B}_{2} \mathrm{H}_{6}, \mathrm{~B}_{5} \mathrm{H}_{9}$, and $\mathrm{B}_{3} \mathrm{~N}_{3} \mathrm{H}_{6} \cdot{ }^{43}$ The negligible amount of impurities in the case of guanidinium octahydrotriborate may be due to the improved ratio of $\mathrm{H}^{+}$to $\mathrm{H}^{-}$, i.e., from 3:6 and 3:5 in $\mathrm{NH}_{4} \mathrm{~B}_{3} \mathrm{H}_{8}$ and $\left(\mathrm{NH}_{3}\right)_{2} \mathrm{BH}_{2} \mathrm{~B}_{3} \mathrm{H}_{8}$, to $3: 4$ in $\mathrm{C}\left(\mathrm{NH}_{2}\right)_{3} \mathrm{~B}_{3} \mathrm{H}_{8}$. In addition, the highly mobile $\mathrm{C}\left(\mathrm{NH}_{2}\right)_{3}{ }^{+}$and $\mathrm{B}_{3} \mathrm{H}_{8}{ }^{-}$in the liquid state could effectively contribute to the combination of $\mathrm{H}^{+}$with $\mathrm{H}^{-}$upon heating, without the need to overcome a mass transfer barrier as in all the solid crystalline octahydrotriborates. More efficient $\mathrm{H}_{2}$ evolution via the combination of $\mathrm{H}^{+}$and $\mathrm{H}^{-}$is the result, and at the same time, the formation of volatile species is suppressed.

\section{Decomposition in solvents}

Being liquid at room temperature gives guanidinium octahydrotriborate a great potential as an injectable hydrogen carrier, which would effectively facilitate the control of hydrogen evolution in terms of both rates and quantity, using the current liquid fuel distribution techniques. To test the feasibility, 0.1 $\mathrm{mol} / \mathrm{L}$ guanidinium octahydrotriborate in THF solution was heated to different temperatures. THF was used to separate $\mathrm{NaCl}$ from the product and to reduce the viscosity of the guanidinium octahydrotriborate. The concentration can be adjusted to maximize the capacity. Other high boiling point solvents such as dimethyl sulfoxide have also been tried with similar results obtained (not shown here). The released gas was analysed by MS (Fig. 5). When heated at $90{ }^{\circ} \mathrm{C}, \mathrm{H}_{2}$ is released with high purity. Note that the peak at $40 \mathrm{amu}$ in Fig. 5 is associated with argon. In total, 3.9 equiv. $\mathrm{H}_{2}$ was released at $90{ }^{\circ} \mathrm{C}$ in 1 hour (see Table 1). When the solution was treated at $100{ }^{\circ} \mathrm{C}$, the dehydrogenation took place in multiple steps (Fig. 6). About 6.5 equiv. or 12.9 wt.\% $\mathrm{H}_{2}$ in all was released after $95 \mathrm{~h}$, with about 4 equiv. $\mathrm{H}_{2}$ released in the first hour and the other 2.5 equiv. $\mathrm{H}_{2}$ over the remaining time (Table 1 and Fig. 6). Solution ${ }^{11} \mathrm{~B}$ NMR spectra were collected during this period (Fig. S5). Most guanidinium octahydrotriborate decomposed in less than $30 \mathrm{~min}$, as the resonance associated with $\mathrm{B}_{3} \mathrm{H}_{8}{ }^{-}$became very weak, while trace amounts of $\mathrm{B}_{2} \mathrm{H}_{6}$ (present as $\mathrm{THF} \cdot \mathrm{BH}_{3}$ at $-0.4 \mathrm{ppm})$ and $\mathrm{B}_{3} \mathrm{~N}_{3} \mathrm{H}_{6}(27.5 \mathrm{ppm})$ were produced. Meanwhile, a large amount of precipitate was found. Since mass transport in solvent is faster than in a solid, the subsequent hydrogen evolution is slow. Both $\mathrm{B}_{2} \mathrm{H}_{6}$ and $\mathrm{B}_{3} \mathrm{~N}_{3} \mathrm{H}_{6}$ participate in the subsequent reaction(s), since they were not observed after 6.5 equiv. $\mathrm{H}_{2}$ was released (Fig. S5).

Table 1: $\mathrm{H}_{2}$ evolution at different temperatures and on different time scales.

\begin{tabular}{ccc}
\hline Temperature $\left({ }^{\circ} \mathrm{C}\right)$ & Time $(\mathrm{h})$ & Equiv. $\mathrm{H}_{2}$ \\
\hline 90 & 1 & 3.9 \\
90 & 50 & 4.1 \\
100 & 1 & 4.0 \\
100 & 95 & 6.5 \\
\hline
\end{tabular}


Solvent alters the decomposition pathway of guanidinium octahydrotriborate. Without solvent, the compound decomposes at about $70{ }^{\circ} \mathrm{C}$, and there was no further decomposition at higher temperatures. The VR results revealed $\sim 6.9 \mathrm{wt} \% \mathrm{H}_{2}$ released at $83.5{ }^{\circ} \mathrm{C}$. When guanidinium octahydrotriborate is added to THF, however, there are stepwise release of $\mathrm{H}_{2}$ at $100{ }^{\circ} \mathrm{C}$, and 12.9 wt. $\% \mathrm{H}_{2}$ is ultimately released. The solvent contributes to the interactions between the hydrogen-rich cations and anions. This is in contrast to the slower mass transfer in the solid-state reaction.
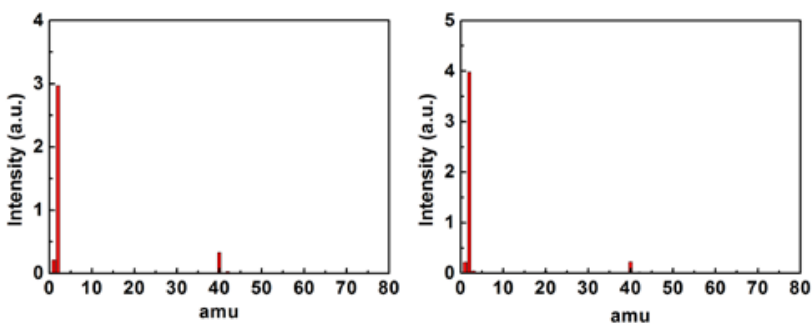

Fig. 5 MS spectra of the gaseous products from $0.1 \mathrm{~mol} / \mathrm{L}$ guanidinium octahydrotriborate in THF at $90{ }^{\circ} \mathrm{C}$ (left), and 100 ${ }^{\circ} \mathrm{C}$ (right).

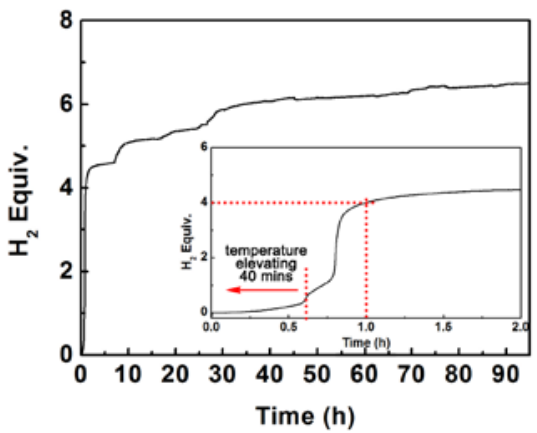

Fig. $6 \mathrm{H}_{2}$ release profile of $0.1 \mathrm{~mol} / \mathrm{L}$ guanidinium octahydrotriborate in $\mathrm{THF}$ at $100^{\circ} \mathrm{C}$ (inset is the first $2 \mathrm{~h}$ ).

Concentration effects were considered in the first two hours. From the dehydrogenation curve (Fig. 7), the $0.1 \mathrm{~mol} / \mathrm{L}$ solution features a two-step hydrogen release, while the $0.5 \mathrm{~mol} / \mathrm{L}$ and $1 \mathrm{~mol} / \mathrm{L}$ solutions feature only one step. MS analysis (Fig. S6) indicates that the concentration does not affect the purity of the $\mathrm{H}_{2}$. There is a slight decline in quantity, however, from 0.1 $\mathrm{mol} / \mathrm{L}$ to $0.5 \mathrm{~mol} / \mathrm{L}$, and then to $1 \mathrm{~mol} / \mathrm{L}$.

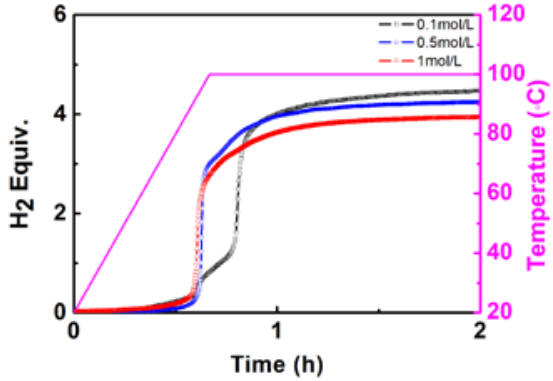

Fig. 7 Hydrogen release from guanidinium octahydrotriborate at different concentrations in THF with heating up to $100{ }^{\circ} \mathrm{C}$.

\section{Solid products characterizations}

Solid-state ${ }^{11} \mathrm{~B}$ and ${ }^{13} \mathrm{C}$ MAS NMR spectroscopy (Figs. 8 and 9), which give the coordination environments of $B$ and $C$, were employed to study the solid products. Solid samples were collected at two points for $0.1 \mathrm{~mol} / \mathrm{L}$ guanidinium octahydrotriborate in THF: after release of about 4 equiv. $\mathrm{H}_{2}$ (4 D for short) and after release of 6.5 equiv. $\mathrm{H}_{2}$ (6.5 D for short).
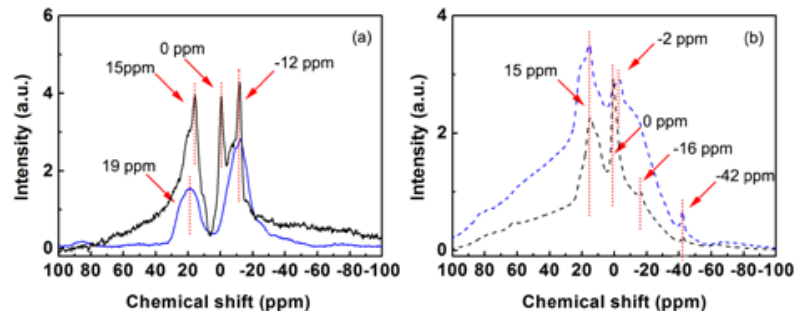

Fig. 8 Solid state MAS ${ }^{11} \mathrm{~B}$ NMR of the precipitate: (a) ${ }^{11} \mathrm{~B}$ MAS cross-polarization NMR and (b) ${ }^{11} \mathrm{~B}$ MAS one-pulse NMR. Blue line: $4 \mathrm{D}$ products; black line: $6.5 \mathrm{D}$ products.

Cross-polarization and one-pulse ${ }^{11} \mathrm{~B}$ MAS NMR were both performed (Fig. 8). Signals at $-42 \mathrm{ppm}$ can be assigned to $\mathrm{BH}_{4}$. The small peaks at $-16 \mathrm{ppm}$ and at $-12 \mathrm{ppm}$ are related to tetra-coordinated B species, ${ }^{26,29}$ with the differences in shift arising from the different coordination environments. Other shifts at $-2 \mathrm{ppm}, 0 \mathrm{ppm}, 15 \mathrm{ppm}$, and $19 \mathrm{ppm}$ correspond to tricoordinated B species such as $-\mathrm{BN}_{3}$ and/or $-\mathrm{BN}_{2} \mathrm{H}^{22,25,36}$

Solid-state cross-polarization ${ }^{13} \mathrm{C}$ MAS NMR spectra of these two stages were also collected (Fig. 9). They show nearly identical signals, which means that there are no significant changes in the carbon skeleton between these two stages. The ${ }^{13} \mathrm{C}$ MAS NMR spectra both have signals at 159, 69, 63, 35, 26, 20, and $14 \mathrm{ppm}$. The peak at $159 \mathrm{ppm}$ can be assigned to $\mathrm{C}=\mathrm{N}$ double bonds and peaks at 69 and 63 ppm to C-N single bonds. From 4 $\mathrm{D}$ to $6.5 \mathrm{D}$, the main changes are the increase in intensity for the peak at $63 \mathrm{ppm}$ and the decrease for peak at $69 \mathrm{ppm}$. Therefore, the peak at $69 \mathrm{ppm}$ is likely to be associated with an intermediate, which could further dehydrogenate to certain species linked to the peak at $63 \mathrm{ppm}$. To validate this, the $6.5 \mathrm{D}$ products were further treated at $120^{\circ} \mathrm{C}$ for $3 \mathrm{~h}$ under dynamic 
vacuum, after which, the peak at 69 ppm nearly disappeared, and only the peak at $63 \mathrm{ppm}$ remained (Fig. S7). Normally peaks at $15-40 \mathrm{ppm}$ are indicative of $\mathrm{C}-\mathrm{H}$ single bonds ${ }^{29}$, but there are no $\mathrm{C}-\mathrm{H}$ bonds in the starting materials. The Fourier transform infrared (FTIR) results confirm the existence of C-H stretching vibrations in $4 \mathrm{D}$ and $6.5 \mathrm{D}$ (Fig. S8). These may come from the residual solvent, since there is a chance that the THF was not removed completely, although the formation of C$\mathrm{H}$ bonds during the dehydrogenation of guanidinium octahydrotriborate is also likely.

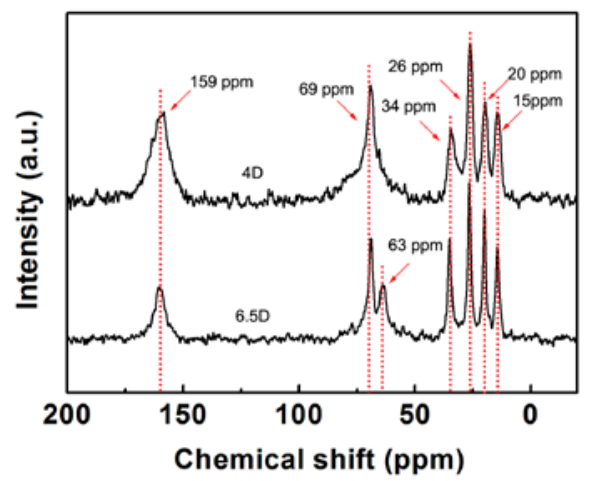

Fig. 9 Cross-polarization MAS ${ }^{13} \mathrm{C}$ NMR spectra of the $4 \mathrm{D}$ and $6 \mathrm{D}$ products.

To elucidate the origins of the C-H bonds, TPD-MS was employed to monitor the thermal decomposition of the $6.5 \mathrm{D}$ products (Fig. S9). THF, diborane, and ammonia were not detected, while only trace amounts of hydrogen were released from $150-250{ }^{\circ} \mathrm{C}$. Furthermore, another ${ }^{13} \mathrm{C}$ NMR spectrum was collected on the $6.5 \mathrm{D}$ products, which were further treated at $120{ }^{\circ} \mathrm{C}$ for $3 \mathrm{~h}$ under dynamic vacuum. Under these conditions, the THF can be removed nearly completely due to its high volatility. The peaks at $15-40 \mathrm{ppm}$ are still visible (Fig. S7). Based upon these results, it can be said that $\mathrm{C}-\mathrm{H}$ bonds are formed in the dehydrogenated products. Due to the typical high bonding energy of $\mathrm{C}-\mathrm{H}$, this portion of the hydrogen would be difficult to extract under the applied experimental conditions.

After the dehydrogenation at $100{ }^{\circ} \mathrm{C}$, a very weak chemical shift associated with $-\mathrm{B}_{3} \mathrm{H}_{8}$ was detected in the solution ${ }^{11} \mathrm{~B}$ NMR spectrum (Fig. S5), and a weak shift correlated to $-\mathrm{BH}_{4}$ was detected in the solid state ${ }^{11} \mathrm{~B}$ NMR spectrum (Fig. 8). The formation of $-\mathrm{BH}_{4}$ during the thermal decomposition of $-\mathrm{B}_{3} \mathrm{H}_{8}$ has been reported. ${ }^{43}$ The observed trace amounts of hydrogen at $150-250{ }^{\circ} \mathrm{C}$ from the precipitate (Fig. S9) is likely to be due to the decomposition of the $-\mathrm{BH}_{4}$ species. The appearance of different tetra- and tri-coordinated B environments (Fig. 8) is commonly observed in the decomposition products of $\mathrm{BNH}$ compounds. ${ }^{29,44,45}$ These are similar to the results of thermal decomposition of guanidinium borohydride, where protic and hydridic hydrogens combine to form $\mathrm{H}_{2}$ and B-N bonds and polymerize to form a precipitate at the same time. ${ }^{29}$ The precipitate has a lower mass transfer rate, so the evolution rate of $\mathrm{H}_{2}$ decreases. Besides the release of hydrogen, there is partial hy- drogenation of carbon. For practical applications, the formation of the precipitate during dehydrogenation would require offboard digestion and regeneration of the spent fuel.

For solutions with different concentrations, the resultant solid products feature slightly different structural features, as evidenced by the solid-state NMR spectra (Figs. S10 and S11). In the solid state MAS cross-polarization ${ }^{11} \mathrm{~B}$ NMR, the broad peak at $19 \mathrm{ppm}$ shifts to $22.2 \mathrm{ppm}$ and $26.7 \mathrm{ppm}$ when the concentration increases. For the MAS cross-polarization ${ }^{13} \mathrm{C}$ NMR, when the concentration increases, the peaks at $26 \mathrm{ppm}$ and 69 ppm become weak, while the peak at $63 \mathrm{ppm}$ increases in intensity. Since the concentration has a slight impact on the amount of hydrogen evolved (Fig. 7), the remaining hydrogen is responsible for the differences in the $\mathrm{C}$ and $\mathrm{B}$ coordination environments, but the main framework of the dehydrogenated products is similar in all cases.

The solid product from decomposition at $100{ }^{\circ} \mathrm{C}$ for $95 \mathrm{~h}$ in THF bears some similarities to the remains of the guanidinium octahydrotriborate decomposed without solvent. The products of these two different dehydrogenation methods are similar in respect to the $\mathrm{B}$ environments. (Fig. S12). For the $\mathrm{C}$ coordination environments, the main peak at $159 \mathrm{ppm}$ related to $\mathrm{C}=\mathrm{N}$ appears under both conditions (Fig. S13), but the intensity of this peak for decomposition in THF is much weaker. This indicates that the guanidinium cation structure has largely disappeared when more $\mathrm{H}$ is released $\left(6.5 \mathrm{H}_{2}\right.$ released versus $\left.5.5 \mathrm{H}_{2}\right)$.

\section{Conclusions}

Guanidinium octahydrotriborate, with a high hydrogen content of $13.8 \mathrm{wt} . \%$, has been successfully synthesized. It behaves like an ionic liquid with a melting point below $-10{ }^{\circ} \mathrm{C}$. Its liquid state could effectively facilitate $\mathrm{H}_{2}$ supply upon demand using the current liquid fuel distribution techniques. High purity $\mathrm{H}_{2}$, as evidenced by MS analysis, was released at a temperature as low as $70{ }^{\circ} \mathrm{C}$. Quantitative measurements demonstrated that about 6.9 wt.\% (if excluding $\mathrm{NaCl}, 11.2$ wt.\%) hydrogen can be released at $83.5{ }^{\circ} \mathrm{C}$ within a short period. When dissolved in THF, about 4 equiv. $\mathrm{H}_{2}$ (7.9 wt.\% based on guanidinium octahydrotriborate) was released in less than $1 \mathrm{~h}$, and about 6.5 equiv. $\mathrm{H}_{2}$ (12.9 wt.\% based on guanidinium octahydrotriborate) was released after an extended period. High purity $\mathrm{H}_{2}$ with negligible amounts of impurities was confirmed by the MS spectra. During the dehydrogenation, solid spent fuel is formed, which slowly gives off trace amounts of $\mathrm{H}_{2}$ upon further heating. To fully evaluate this compound for hydrogen storage, further tests on the thermal stability, vapour pressure, and viscosity in various solvents, as well as the changes in these properties with temperature and the temperature dependent kinetics, are needed.

\section{Acknowledgements}

This work is financially supported by the National Natural Science Funds for Distinguished Young Scholars (project number 51225206), the National Natural Science Foundation of China (project numbers U1232120, 51301161, and 51472237) and the Australian Research Council's Discovery Projects funding 
scheme (project number DP140102858). W. Chen is grateful for a scholarship from the Chinese Academy of Sciences and for the support from the University of Wollongong for his oneyear visit. Z. Huang is the recipient of an Australian Research Council Discovery Early Career Research Award (project number DE120101496). The authors thank Xiaohua Ju and Dong Xie for their help in using solid state NMR.

\section{Notes and references}

${ }^{a}$ Dalian National Laboratory for Clean Energy, Dalian Institute of Chemical Physics, Chinese Academy of Sciences, 457 Zhongshan Road, Dalian 116023 (China). E-mail: pchen@dicp.ac.cn

${ }^{b}$ University of the Chinese Academy of Sciences, Beijing 100039 (China).

${ }^{c}$ Institute for Superconducting and Electronic Materials, University of Wollongong, Squires Way, North Wollongong, New South Wales, 2522 (Australia). Email: zhenguo@uow.edu.au.

Electronic Supplementary Information (ESI) available:

XRD pattern of the solid formed during the synthesis, melting point and DTA measurements, concentration effects tests, MS analysis of the gaseous products, solution ${ }^{11} \mathrm{~B}$ NMR spectra, solid state ${ }^{11} \mathrm{~B}$ and ${ }^{13} \mathrm{C}$ NMR spectra, FTIR measurements, TPD-MS measurements. See DOI:10.1039/b000000x/.

1. L. Schlapbach and A. Zuttel, Nature, 2001, 414, 353-358.

2. S. I. Orimo, Y. Nakamori, J. R. Eliseo, A. Zuttel and C. M. Jensen, Chem. Rev., 2007, 107, 4111-4132.

3. R. Custelcean and J. E. Jackson, Chem. Rev., 2001, 101, 19631980.

4. F. H. Stephens, V. Pons and R. T. Baker, Dalton Trans., 2007, 2613-2626.

5. $\quad$ B. Peng and J. Chen, Energy Environ. Sci., 2008, 1, 479-483.

6. C. W. Hamilton, R. T. Baker, A. Staubitz and I. Manners, Chem. Soc. Rev., 2009, 38, 279-293.

7. A. Staubitz, A. P. M. Robertson and I. Manners, Chem. Rev., 2010, 110, 4079-4124.

8. P. Wang, Dalton Trans., 2012, 41, 4296-4302.

9. Z. G. Huang and T. Autrey, Energy Environ. Sci., 2012, 5, $9257-$ 9268.

10. X. N. Chen, J. C. Zhao and S. G. Shore, Acc. Chem. Res., 2013, 46, 2666-2675.

11. G. Wolf, J. Baumann, F. Baitalow and F. P. Hoffmann, Thermochim. Acta, 2000, 343, 19-25.

12. F. Baitalow, J. Baumann, G. Wolf, K. Jaenicke-Rossler and G. Leitner, Thermochim. Acta, 2002, 391, 159-168.

13. P. Wang and X. D. Kang, Dalton Trans., 2008, 5400-5413.

14. J. H. Wang, T. Liu, G. T. Wu, W. Li, Y. F. Liu, C. M. Araujo, R. H. Scheicher, A. Blomqvist, R. Ahuja, Z. T. Xiong, P. Yang, M. X. Gao, H. G. Pan and P. Chen, Angew. Chem. Int. Ed., 2009, 48, 5828-5832.

15. Z. Xiong, C. K. Yong, G. Wu, P. Chen, W. Shaw, A. Karkamkar, T. Autrey, M. O. Jones, S. R. Johnson and P. P. Edwards, Nat. Mater., 2007, 7, 138-141.

16. H. V. K. Diyabalanage, R. P. Shrestha, T. A. Semelsberger, B. L. Scott, M. E. Bowden, B. L. Davis and A. K. Burrell, Angew. Chem. Int. Ed., 2007, 46, 8995-8997.

17. J. J. Vajo, S. L. Skeith and F. Mertens, J. Phys. Chem. B, 2005, 109, 3719-3722.

18. W. T. Klooster, T. F. Koetzle, P. E. M. Siegbahn, T. B Richardson and R. H. Crabtree, J. Am. Chem. Soc., 1999, 121, 6337-6343.

19. W. Grochala and P. P. Edwards, Chem. Rev., 2004, 104, 12831315.

20. Y. J. Yang, Y. F. Liu, Y. Li, M. X. Gao and H. G. Pan, J. Phys. Chem. C, 2013, 117, 16326-16335.

21. X. Zheng, G. Wu, W. Li, Z. Xiong, T. He, J. Guo, H. Chen and P. Chen, Energy Environ. Sci., 2011, 4, 3593-3600.
22. Y. Guo, G. Xia, Y. Zhu, L. Gao and X. Yu, Chem. Commun., 2010, 46, 2599-2601.

23. F. E. Pinkerton, G. P. Meisner, M. S. Meyer, M. P. Balogh and M. D. Kundrat, J. Phys. Chem. B, 2005, 109, 6-8.

$24 . \quad$ G. Soloveichik, J. H. Her, P. W. Stephens, Y. Gao, J. Rijssenbeek, M. Andrus and J. C. Zhao, Inorg. Chem., 2008, 47, 4290-4298.

25. T. J. Groshens and R. A. Hollins, Chem. Commun., 2009, 30893091.

26. Y. H. Guo, Q. F. Gu, Z. P. Guo, J. F. Mao, H. K. Liu, S. X. Dou and X. B. Yu, J. Mater. Chem., 2011, 21, 7138-7144.

27. Z. Tang, Y. Guo, S. Li and X. Yu, J. Phys. Chem. C, 2011, 115, 3188-3193.

$28 . \quad$ L. G. Li, S. F. Li, Y. B. Tan, Z. W. Tang, W. Y. Ca, Y. H. Guo, Q. Li and X. B. Yu, J. Phys. Chem. C, 2012, 116, 14218-14223.

$29 . \quad$ A. Doroodian, J. E. Dengler, A. Genest, N. Roesch and B. Rieger, Angew. Chem. Int. Ed., 2010, 49, 1871-1873.

30. M. Chong, A. Karkamkar, T. Autrey, S. Orimo, S. Jalisatgi and C. M. Jensen, Chem. Commun., 2011, 47, 1330-1332.

31. Z. Huang, X. Chen, T. Yisgedu, J.-C. Zhao and S. G. Shore, Int. J. Hydrog. Energy, 2011, 36, 7038-7042.

32. C. W. Yoon and L. G. Sneddon, J. Am. Chem. Soc., 2006, 128, 13992-13993.

33. C. W. Yoon, P. J. Carroll and L. G. Sneddon, J. Am. Chem. Soc., 2009, 131, 855-864.

34. C. L. Aardahl and S. D. Rassat, Int. J. Hydrog. Energy, 2009, 34, 6676-6683.

35. M. Burchner, A. M. T. Erle, H. Scherer and I. Krossing, Chem. Eur. J., 2012, 18, 2254-2262.

36. L. V. Titov, M. D. Levicheva and G. N. Dubikhina, Russ. Chem. Bull., 1976, 25, 1747-1749.

37. H. Gao and J. n. M. Shreeve, J. Mater. Chem., 2012, 22, 1102211024.

38. Q. Zhang and J. n. M. Shreeve, Chem. Eur. J., 2013, 19, 1544615451.

39. P. V. Ramachandran, A. S. Kulkarni, M. A. Pfeil, J. D. Dennis, J. D. Willits, S. D. Heister, S. F. Son and T. L. Pourpoint, Chem. Eur. J., 2014, 20, 16869-16872.

40. S. Li, H. Gao and J. n. M. Shreeve, Angew. Chem. Int. Ed., 2014, 53, 2969-2972.

41. Z. Huang, G. King, X. Chen, J. Hoy, T. Yisgedu, H. K. Lingam, S. G. Shore, P. M. Woodward and J.-C. Zhao, Inorg. Chem., 2010, 49, 8185-8187.

42. R. Checchetto, G. Trettel and A. Miotello, Meas. Sci. Technol., 2004, 15, 127-130.

43. Z. G. Huang, M. Eagles, S. Porter, E. G. Sorte, B. Billet, R. L. Corey, M. S. Conradi and J. C. Zhao, Dalton Trans., 2013, 42, 701-708.

$44 . \quad$ A. D. Sutton, A. K. Burrell, D. A. Dixon, E. B. Garner, J. C. Gordon, T. Nakagawa, K. C. Ott, P. Robinson and M. Vasiliu, Science, 2011, 331, 1426-1429.

$45 . \quad$ C. A. Jaska, K. Temple, A. J. Lough and I. Manners, Chem. Commun., 2001, 962-963. 